\title{
УДК 327.3
}

\section{Борис ГУСЕЛЕТОВ}

\section{ПАРТИЯ ЕВРОПЕЙСКИХ СОЦИАЛИСТОВ В ПОЛИТИЧЕСКОЙ СИСТЕМЕ ЕС}

Статья поступила в редакцию 10.02.2021

\begin{abstract}
Аннотация. В статье представлен анализ единого европейского общественнополитического пространства и взаимодействия Партии европейских социалистов (ПЕС) с институтами Евросоюза. Сделан вывод, что постепенно меняется формат отношений отдельных европартий, в частности Партии европейских социалистов, традиционно выступающей за расширение связей между властью и гражданами, с европейским гражданским обществом и ключевыми политическими институтами Евросоюза (Европейский совет, Еврокомиссия и Европарламент). На основе материалов о деятельности Партии европейских социалистов показано, что этой организации удалось создать конкретные инструменты и механизмы укрепления связей с гражданскими активистами (так называемые сети ПЕС по различным проблемам), национальными партиями-членами, а также все более активно вовлекать в свою работу представителей партии в Евросовете, Еврокомиссии и Европарламенте. Это свидетельствует о продолжении процесса становления общеевропейского политического пространства и появлении в нем все более активных политических и гражданских акторов, влияющих на формирование европейской повестки дня.

Ключевые слова: Евросоюз, европейские партии, Европарламент, Еврокомиссия, Партия европейских социалистов, европейское политическое пространство, гражданское общество, национальные партии.
\end{abstract}

До начала XXI столетия Европейского союза приоритетной целью была экономическая интеграция, в то время как формирование единого общественно-политического пространства оставалось второстепенной задачей. В силу этого сложившиеся общеевропейские политические институты - Европейский совет, Еврокомиссия (ЕК), Европарламент (ЕП), европартии, общеевропейские неправительственные организации и др. - оставались в сильной зависимости от руководства стран-членов ЕС и их общественно-политических институтов (национальные партии и НКО).

Однако с 2008-2009 гг. ситуация начала постепенно меняться, и общеевропейские политические институты начали трансформироваться в более самостоятельные субъекты. Это было связано, в первую очередь, с мировым финансовоэкономическим кризисом. Не случайно именно в этот период в европейском поли-

(C) Гуселетов Борис Павлович - д.полит.н., ведущий научный сотрудник Центра партийнополитических исследований, Институт Европы РАН. Адрес: 125009 , Россия, Москва, Моховая улица, 11-3.E-mail: bgusletov@mail.ru

DOI: http://dx.doi.org/10.15211/soveurope320218393 
тическом и экспертном сообществе началось обсуждение этой проблемы [Kaiser, W., Starie, P., 2009, Duff, A., 2010], которое носило в основном общетеоретический характер.

Произошедшие во втором десятилетии XXI века события - миграционный кризис 2015-2016 гг., выход Британии из ЕС, осложнение отношений между Берлином и Вашингтоном после избрания Трампа, относительный успех жестких евроскептиков на европейских выборах 2019 г. и другие - еще больше актуализировали проблему формирования общеевропейского общественно-политического пространства, что нашло свое отражение в ряде недавних публикаций [Habermas, J., 2015; Trondal, J., 2017; Westlake, M., 2017; Lehne, 2019], авторы которых пытались более предметно исследовать данное явление. Основной целью был анализ принципа «Ведущего кандидата» (Spitzenkandidaten), трансформация взаимоотношений между европейским и национальным политическим истеблишментом и бизнес-элитами, изменение расклада политических сил в Европарламенте и прочее.

Между тем очевидно, что формирование реального общеевропейского общественно-политического пространства невозможно без радикального изменения роли европартий и институтов европейского гражданского общества и их влияния на формирование и политику ключевых политических институтов ЕС.

Проделанный автором анализ деятельности ведущих европартий, представленных в Европарламенте, за последние два года показал, что наибольшего прогресса в решении рассматриваемой проблемы добилась Партия европейских социалистов, сумевшая создать устойчивые механизмы взаимодействия между НКО, депутатами ЕП от ПЕС и ее представителями в ЕК и Евросовете.

Исходя из этого, предметом данного исследования является взаимодействие европейских политических партий с институтами Евросоюза на примере Партии европейских социалистов.

Актуальность выбранной темы определяется следующими причинами:

- объективно происходящей трансформацией института политических партий в условиях глобализации и развития цифровых технологий, связанной с поиском новых моделей и механизмов взаимодействия этих партий с представителями гражданского общества и властными институтами;

- возникновением в середине 70-х годов XX в. на европейской политической арене общеевропейских политических партий (европартий);

- наметившимся изменением во взаимоотношениях между европартиями, ведущими политическими институтами Евросоюза (Европейский совет, Еврокомиссия и Европарламент) и гражданским обществом, вызванным недовольством европейских избирателей бюрократическим характером этих институтов, а также укреплением связей между отдельными европартиями и их представителями в указанных выше политических институтах ЕС. Данная тенденция особенно свойственна ПЕС, традиционно выступающей за укрепление влияния гражданского общества на органы власти.

\section{Об эволюции института общеевропейских партий (европартий)}

Европейская политическая партия (европартия) - это особый тип партии, действующей на транснациональном уровне, а также в политических институтах ЕC. Традиционно эти партии состоят из национальных партий, имеющих общую идео- 
логическую ориентацию. В ряде европартий допускается персональное членство. Их деятельность регулирует и финансирует Евросоюз. Они имеют исключительное право проводить предвыборные кампании во время общеевропейских выборов и создавать по их итогам собственные фракции в Европарламенте. Европартии посредством проведения совещаний с участием ассоциированных с ними глав государств и правительств могут оказывать влияние на процесс принятия решений в Европейском совете. Они также тесно сотрудничают и координируют свою деятельность с ассоциированными членами Еврокомиссии. В соответствии с Лиссабонским договором, европартия, победившая на европейских выборах, имеет право предложить Евросовету своего кандидата на пост председателя Еврокомиссии.

Процесс изучения феномена европартий, по мнению нидерландского исследователя C. ван Гекке [van Hecke, S., 2010], прошел четыре этапа. Первый из них был связан с проведением первоначальных выборов депутатов Европарламента 1979 г., после чего многие предполагали появление на политической арене Европы первых европартий, которые должны были занять доминирующее положение в европейской партийной системе [Reif, K., 1984; Niedermayer, O., 1984; Beyme, K. von, 1985].

Второй этап совпал с принятием в 1992 г. Маастрихского договора, в статье 138а которого впервые была официально указана роль европартий в политической системе $\mathrm{EC}^{1}$, хотя уже тогда во многих странах Союза был отмечен рост неприятия процесса европейской интеграции [Hanley, D., 1994; Hix, S. and Lord, C., 1997; Johansson, K. M., 1999].

Третий этап пришелся на 2004-2010 гг. - период присоединения к ЕС ряда стран из Центральной и Восточной Европы, а также формирования общеевропейской нормативно-правовой основы, регулирующей деятельность европартий и связанных с ними новых общеевропейских фондов. Для этого периода был характерен рост числа таких партий, который привел к заметному усилению их идеологического разнообразия [Raunio, T., 2006; Usherwood, S., 2007; van Hecke, S., 2010].

Наконец, четвертый этап (2014-2018 гг.) был связан с принципом «ведущий кандидат» (Spitzenkandidaten) [Külahci E., Lightfoot S., 2014; Schmitt, H., Hobolt, S. and Popa, S., 2014; Day, S., 2014; van Hecke, S., 2018; Потемкина O., 2018], что, по мнению ряда экспертов, должно было придать европартиям больше веса и влияния при формировании одного из ключевых политических институтов Евросоюза - Европейской Комиссии. Как показали европейские выборы (имеются в виду выборы в Европарламент) 2014-2019 гг., практическая реализация этого принципа проходит с большим трудом, что в первую очередь связано с нежеланием глав государств-членов ЕС делиться своими полномочиями в вопросе утверждения главы ЕК. Практически все европартии, представленные в ЕП, поддерживают этот принцип и настроены добиваться его безусловного применения в соответствии с духом Лиссабонского договора.

Европейские выборы 2019 г. ознаменовали собой начало пятого этапа исследования института ЕП. В этот период усиливается противостояние между еврооптимистами и евроскептиками, меняется формат отношений между европартиями и ключевыми политическими институтами ЕС и пр. [Ривера Э., Дэвис М., Буневич Д.,

1 Treaty on European Union - Contents Official Journal C 306, 17/12/2007. P. 15. URL: https://mgimo.ru/files2/y11_2013/243404/3.6.treaty_lisbon.pdf. (дата обращения: 12.02.2021)

Современная Европа, 2021, № 3 
2019; Kolster C., Von Homeyer H. 2019; Clasen P. 2020, Hoppe A., Schmälter J. 2020, Кавешников Н.Ю. 2020; Гуселетов Б.П. 2020, 2021].

Действительно, до недавнего времени большинство ученых считали, что от традиционных политических партий, действующих на национальном уровне, европартии заметно отличаются тем, что не имеют реальных корней в гражданском обществе и практически не влияют на формирование и деятельность ведущих политических институтов ЕС. Более того, они слабо связаны со своими партиями-членами из европейских стран. Например, ван Гекке в одной из своих недавних работ писал о европартиях, что «их роль по-прежнему в значительной степени незаметна, и они не всегда участвуют в важнейших общеевропейских инициативах». В этой же работе он отмечал, что «европейские политические партии должны играть большую роль как внутри, так и за пределами “брюссельского пузыря", особенно во время европейских избирательных кампаний и между выборами». Он даже выдвинул ряд предложений, направленных на улучшение взаимоотношений между европартиями и гражданами ЕС, европейским гражданским обществом, национальными партиями и органами власти и общеевропейскими политическими институтами [van Hecke, S., 2018: 8-10].

О необходимости усилить роль и влияние европартий говорил и бывший глава Еврокомиссии Ж.-К. Юнкер в своей речи перед депутатами Европарламента «О состоянии Евросоюза» в 2017 г. Он отметил: «Комиссия предлагает новые правила финансирования политических партий... Мы должны дать европартиям возможность лучше организоваться. Я поддерживаю идею транснациональных списков на европейских выборах... Если вы хотите укрепить европейскую демократию, то вы не можете обратить вспять демократический прогресс, наблюдаемый с введением процедуры ведущих кандидатов - “Spitzenkandidaten”. Мне хотелось бы, чтобы этот опыт повторился» ${ }^{1}$.

Что касается конкретных европартий, то из десяти официально зарегистрированных Евросоюзом пока не все сумели трансформировать свою деятельность таким образом, чтобы укрепить свое влияние на общеевропейском уровне. Наибольшего успеха в этом направлении добилась Партия европейских социалистов (ПЕС) [Clasen, Р. (2020)]. Рассмотрим более подробно итоги деятельности ПЕС за последние два года.

Основные приоритеты ПЕС

Ключевые приоритеты в деятельности ПЕС были изложены в ее предвыборном Манифесте, обнародованном накануне европейских выборов 2019 г. В нем отмечено, что ПЕС предлагает новый гражданский договор, основными элементами которого являются:

- укрепление единства Европы при уважении к ее разнообразию, являющемуся ее общим достоянием;

- сокращение неравенства и концентрации богатства и собственности в руках привилегированного меньшинства. Защита тех, кто потерял работу, здоровье или переживает трудные времена;

1 European Commission, (2017) 'President Jean-Claude Juncker's State of the Union Address 2017', Brussels, 13.09.2017, URL: reconnecting-european-political-parties-with-european-unioncitizens.pdf. (дата обращения: 12.02.2021)

Современная Европа, 2021, № 3 
- широкое гражданское участие в общественных делах, подотчетность всех органов власти, прозрачность и справедливость процесса принятия решения на всех уровнях;

- защита окружающей среды, борьба с изменением климата, сохранение биоразнообразия, принятие Пакта об устойчивом развитии с ясными социальными и экологическими целями;

- обеспечение лучших перспектив для молодежи и обеспечение того, чтобы пожилые люди перестали чувствовать неуверенность в дальнейшей жизни;

- борьба с любыми формами дискриминации, принятие Стратегии гендерного равенства;

- развитие и укрепление партнерства с развивающимися странами, обеспечение справедливой политики предоставления убежища и миграции, основанной на общей ответственности и солидарности между странами-членами и сотрудничестве со странами происхождения и транзита ${ }^{1}$.

Руководство ПЕС уделяет пристальное внимание укреплению роли европейского гражданского общества в деле разработки и реализации общеевропейской политики, особенно в социальной сфере. Для этого в ПЕС были созданы несколько сетей: Сеть социальная Европа (Social Europe Network, SEN), которую возглавляет евродепутат А. Йонгериус (Партия труда Нидерландов); Сеть по окружающей среде, изменению климата и энергии (ENVI Network), возглавляемая евродепутатом X. Лопесом (Соцпартия Каталонии, Испания); Сеть по миграции и интеграции (Migration and Integration Network, MIN), председателем которой является евродепутат К. Ольссон (Социал-демократическая партия Швеции); Финансово-экономическая сеть (Financial and Economic Network, FEN), возглавляемая Президентом Фонда европейских прогрессивных исследований (мозговой центр ПЕС) М.-Ж. Родригесом (Соцпартия Португалии), в прошлом тоже евродепутатом.

В работе этих сетей обычно участвуют еврокомиссар от ПЕС по соответствующему направлению, евродепутаты, национальные депутаты, гражданские активисты и представители руководства Партии европейских социалистов.

В конце января 2021 г. депутаты ЕП, представители партий и организацийчленов ПЕС, профсоюзов и НКО провели заседание Сети по миграции и интеграции с участием еврокомиссара по внутренним делам Ильвы Йоханссон для обсуждения нового плана действий ЕК по интеграции и включению мигрантов на 2021-2027 гг. Участники заседания обсудили и поддержали план Йоханссон, который основан на признании того, что интеграция мигрантов требует усилий как от них самих, так и от принимающих их стран. Было предложено на основе анализа итогов реализации предыдущего плана действий от 2016 г. включить в представленный план ряд новых направлений работы с мигрантами.

Финансово-экономическая сеть ПЕС в начале 2021 г. поддержала предложения еврокомиссара по экономике П. Джентилони о введении справедливого цифрового налогообложения и противодействии агрессивному налоговому планированию, а также предложение исполнительного вице-президента ЕК Ф. Тиммерманса о нало-

${ }^{1}$ PES Manifesto (2019). A New Social Europe. URL: https://manifesto.frans4eu.eu/. (дата обращения: 12.02.2021) 
ге на загрязнение окружающей среды как инструмента реализации европейской зеленой политики ${ }^{1}$.

Помимо деятельности сетей ПЕС, руководство партии уделяет большое внимание координации действий представителей ее партий-членов на европейском уровне. Для этого под эгидой партии регулярно проводятся встречи министров, являющихся членами национальных правительств от партий-членов ПЕС, с еврокомиссарами и евродепутатами. На них обсуждаются общеевропейские проблемы и согласуются позиции представителей разных стран по их возможному решению. В конце 2020 г. состоялось несколько таких встреч, из которых наиболее важными были три.

В октябре 2020 г. на встрече министров, отвечающих за занятость и социальную политику, в которой приняли участие еврокомиссары Н. Шмит и Х. Далли, а также одиннадцать министров или их заместителей из восьми стран-членов $\mathrm{EC}^{2}$, была принята Совместная декларация об участии работников в организации деятельности на предприятиях и гендерном равенстве. В этом документе отмечалось, что право работника участвовать в принятии решений на предприятии - это краеугольный камень построения социальной Европы, в которой экономический рост сможет обеспечивать социальный прогресс только в том случае, если Евросоюз будет защищать и поощрять участие трудящихся, социальную справедливость и устойчивое развитие. В декларации также отмечалась необходимость обеспечения равной оплаты за равный труд, равных возможностей для карьерного роста и равного распределения обязанностей по уходу за ребенком ${ }^{3}$.

В ноябре 2020 г. на совещании министров иностранных дел и развития от партий-членов ПЕС (присутствовали шесть министров из шести стран-членов ЕС) с участием отвечающего за международное партнерство еврокомиссара Ютты Урпилайнен, была отмечена необходимость поддержать беднейшие страны мира путем предоставления им инвестиций и облегчения их долгового бремени, с тем чтобы каждая из этих стран могла достичь Целей устойчивого развития и эффективно справиться с последствиями кризиса, вызванного пандемией COVID-19 4 .

Наконец, 7 ноября 2020 г. министры по европейским и иностранным делам (присутствовали пять министров из пяти стран-членов ЕС) и глава группы социалистов и демократов в ЕП И.-Г. Перес констатировали, что Европа находится

${ }^{1}$ FEN Network: Fair taxation and economic governance are essential for a real EU recovery. 27.01.2021. URL: https://www.pes.eu/en/news-events/news/detail/FEN-Network-Fair-taxationand-economic-governance-are-essential-for-a-real-EU-recovery/?. (дата обращения: 12.02.2021)

2 PES EPSCO ministers push for a fair recovery for all workers. 13.10.2020. URL: https://www.pes.eu/en/news-events/news/detail/PES-EPSCO-ministers-push-for-a-fair-recoveryfor-all-workers/?\&page=5. (дата обращения: 12.02.2021)

${ }^{3}$ PES ministerial declaration: Workers' participation, a key success factor for Europe's recovery Adopted at the online PES meeting of Employment and Social Affairs Ministers, 13.10.2020. URL: https://www.pes.eu/en/permalink/525cba52-0d2d-11eb-8aa2-9a82572148c5.pdf. (дата обращения: 12.02.2021)

${ }^{4}$ EU must be a global leader on development, PES ministers reaffirm. 23.11.2020. URL: https://pes.eu/news_content.php?id=97. (дата обращения: 12.02.2021)

Современная Европа, 2021, № 3 
на грани глубокого институционального тупика, который может разрушить надежды миллионов людей на успешный выход из экономического и социального кризиса, вызванного пандемией COVID-19. Министры от партий-членов ПЕС заявили, что отказ правых правительств Венгрии и Польши одобрить План восстановления экономики Европы («Новое поколение ЕС») и новый семилетний бюджет не должен привести к отвержению принципа верховенства права и поставить под угрозу усилия по восстановлению экономики и социальной сферы EC. Председательствующий на совещании министр по европейским делам Финляндии Т. Туппурайнен заявил, что «верховенство права - это фундаментальная европейская ценность и основополагающий элемент проекта ЕC, которым нельзя жертвовать. Ни одна страна-член Евросоюза не допустит, чтобы его игнорировали во имя сиюминутных внутриполитических выгод». Эту инициативу подержало Правление ПЕС, которое на своем заседании в декабре 2020 г. с участием членов Евросовета и Еврокомиссии от ПЕС обратилось к венгерскому и польскому правительству с предложением не чинить препятствий в реализации этих начинаний ${ }^{2}$.

Обеспечение скорейшего принятия Европейским советом долгосрочного плана восстановления европейской экономики, названного «Новое поколение ЕС», и нового семилетнего бюджета ЕС на 2021-2027 гг. стало приоритетом ПЕС. В декабре 2020 г. руководство ПЕС (С. Станишев) и ее фракция в ЕП (Спикер ЕП Д. Сассоли и руководитель фракции И.Г. Перес), премьер-министры от партий-членов ПЕС (П. Санчес, Испания, и С. Левен, Швеция) и еврокомиссары-социалисты (Х. Баррель и П. Джентилони) приняли соответствующее обращение к Евросовету. Как отметил Станишев, «Мы не можем войти в 2021 г. с бюджетом 2020 г., как будто пандемии никогда не было. Социалисты готовы поддержать это соглашение» ${ }^{3}$. Незадолго до этого руководство ПЕС обратилось к лидерам Европейской народной партии (ЕНП) и партии Альянс европейских консерваторов и реформистов (ЕКР) поддержать это соглашение.

\section{ПЕС и Европарламент}

Партия европейских социалистов имеет вторую по численности фракцию в Европарламенте - группу социалистов и демократов, насчитывающую 147 евродепутатов. Спикер ЕП Сассоли (Италия) также является членом этой группы. Президент ПЕС Станишев был избран евродепутатом от Болгарии. Пост первого вицепрезидента ПЕС занимает президент группы социалистов и демократов И. Гарсия

${ }^{1}$ PES Europe ministers: the rule of law and the recovery both need to be upheld. 07.12.2020. URL: https://www.pes.eu/en/news-events/news/detail/PES-Europe-ministers-the-rule-of-lawand-the-recovery-both-need-to-be-upheld/?\&page=3. (дата обращения: 12.02.2021)

2 Socialists urge EUCO to reach agreement on recovery and MFF which fully respects the Rule of Law. 10.12.2020. URL: https://www.pes.eu/en/news-events/news/detail/Socialists-urge-EUCOto-reach-agreement-on-recovery-and-MFF-which-fully-respects-the-Rule-of-Law/. (дата обращения: 12.02.2021)

${ }^{3}$ Socialists urge EUCO to reach agreement on recovery and MFF which fully respects the Rule of Law. 21.10.2020. URL: https://www.pes.eu/en/news-events/news/detail/Socialists-urge-EUCOto-reach-agreement-on-recovery-and-MFF-which-fully-respects-the-Rule-of-Law/. (дата обращения: 12.02.2021) 
(Испания), вице-президентами партии являются нынешний евродепутат Е. Фрицон (Швеция) и бывший евродепутат (2009-2014 гг.) К. Неведалова (Словакия).

Все они активно участвуют в работе Президиума и саммитах Партии европейских социалистов накануне заседаний Европейского совета, в ходе которых руководство партии и члены Евросовета, представляющие партии-члены ПЕС, вырабатывают общую позицию, которую они будут отстаивать в ходе заседания.

В работе подготовительного совещания ПЕС накануне саммита Евросовета 10 декабря 2020 г. активное участие, наряду с членами Евросовета П. Санчесом (Испания) и С. Левеном (Швеция), приняли Сассоли и Гарсия ${ }^{1}$.

Руководство ПЕС в последнее время проводит активную работу по привлечению депутатов ЕП из группы социалистов и демократов к работе в сетях партии (почти все из них возглавляют евродепутаты), обсуждению планов и результатов работы еврокомиссаров от Партии европейских социалистов, налаживанию сотрудничества между ПЕС и национальными партиями-членами, а также национальными правительствами, в которых есть министры этих партий.

Депутаты из группы социалистов и демократов традиционно участвуют в тематических совещаниях министров от партий-членов ПЕС, что позволяет вырабатывать более взвешенную и объективную позицию по тем или иным актуальным вопросам европейской политики, с учетом мнений представителей из разных странчленов ЕС. Например, в заседании министров здравоохранения от партий-членов ПЕС, на котором обсуждались вопросы скорейшего одобрения вакцины от COVID19 и принятия долгосрочного плана деятельности европейской фармацевтической промышленности, принимали участие вице-президент группы социалистов и демократов X. Фрицон и координатор от ПЕС по реализации программы работы прогрессивной комиссии П. Маркес ${ }^{2}$.

\section{ПЕС и Еврокомиссия}

Руководство ПЕС заметно усилило свою работу по координации между ее представителями в Евросовете, ЕК, ЕП, институтах гражданского общества, а также лидерами ее партий-членов на фоне кризиса, вызванного пандемией COVID-19. При этом особое внимание уделено взаимодействию с членами Еврокомиссии от партии, поскольку ЕК по-прежнему играет ключевую роль в разработке и практической реализации политики Евросоюза.

Напомним, что в состав новой Еврокомиссии во главе с У. фон дер Ляйен вошло девять представителей ПЕС, которые стремятся непосредственно влиять на разработку и реализацию общеевропейской политики в основных социальноэкономических областях в соответствии с ключевыми приоритетами ПЕС, изложенными в ее предвыборном Манифесте $2019^{3}$. Это стало особенно актуально в

\footnotetext{
${ }^{1}$ Socialists urge EUCO to reach agreement on recovery and MFF which fully respects the Rule of Law... (дата обращения: 12.02.2021)

${ }^{2}$ Covid-19 response must be the start of an improved European cooperation on health. 01.12.2020. URL: https://www.pes.eu/en/news-events/news/detail/Covid-19-response-must-be-the-start-ofan-improved-European-cooperation-on-health/?\&page=3. (дата обращения: 12.02.2021)

3 Manifesto-2019. URL: https://www.pes.eu/export/sites/default/galleries/Documents-gallery/ PES-Manifesto-2019_EN.pdf_2063069299.pdf. (дата обращения: 12.02.2021)
} 
условиях крайне негативных последствий кризиса для ПЕС и ее партий-членов, цель которых - борьба за восстановление социальной справедливости.

Эта работа была исключительно важна на фоне роста активности евроскептических партий, которая стала все более возрастать уже после принятия европейского Пакта стабильности и роста 1997 г., усилившего влияние институтов ЕС на процессы принятия решений на национальном уровне [De la Porte C., Heins E. 2016]. В Австрии, Италии, Нидерландах, Франции и ряде других стран лидеры евроскептиков (Н. Хофер, М. Сальвини, Г. Вилдерс, М. Ле Пен) сумели перехватить у социалдемократов и социалистов социальную повестку дня и перетянули на свою сторону многих традиционных сторонников социал-демократии [Berman S. 2017].

$\mathrm{O}$ важности постоянного и эффективного взаимодействия между партией и ее представителями в ЕК говорил 21 октября 2019 г. президент ПЕС С. Станишев на совместной встрече руководства партии с еврокомиссарами от Партии европейских социалистов. В своей речи он отметил, что «у ПЕС есть сильная команда комиссаров, которые борются за реализацию приоритетов партии, которые включают «европейскую зеленую сделку», высокий стандарт социальных прав граждан и гарантии его реализации, обеспечение гендерного равенства и большей сплоченности европейского гражданского общества и, в конечном итоге, улучшение жизни каждого человека» .

\section{Выводы}

Анализ деятельности руководства Партии европейских социалистов показывает, что в условиях пандемии COVID-19 эта партия, ее представители в политических институтах ЕС (Европейски совет, Еврокомиссия и Европарламент), а также в национальных партиях-членах ПЕС, заметно активизировали свою деятельность на общеевропейском уровне. При этом европейские социалисты все более активно отстаивают свои традиционные принципы: активное участие граждан в общественной жизни, солидарность в деле защиты прав и свобод человека, обеспечение социального равенства и борьба со всеми видами дискриминации.

Представленные новые элементы в деятельности ПЕС, связанные с созданием механизмов регулярного обмена мнениями и информацией между представителями гражданского общества, депутатами парламентов разного уровня, членами национальных правительств и еврокомиссарами, показывают, что эта европартия все активнее стремится бороться с традиционными недостатками в деятельности большинства европартий: отсутствие связи с гражданским обществом, слабое влияние на деятельность органов представительной и исполнительной власти, включая ведущий политический институт Евросоюза - Европейский совет.

Традиционные неолиберальные методы поддержки экономики на уровне Евросоюза за счет жесткой фискальной политики и сокращения расходов на социальную сферу не приносят желаемого результата в период пандемии коронавируса. Предложения социалистов по преодолению последствий кризиса основаны на поддерж-

${ }^{1} 2021$ Commission work programme: EU must deliver on progressive priorities to secure a recovery for all. 21.10.2020. URL: https://www.pes.eu/en/news-events/news/detail/2021-Commissionwork-programme-EU-must-deliver-on-progressive-priorities-to-secure-a-recovery-forall/?\&page=5. (дата обращения: 12.02.2021) 
ке граждан, увеличении инвестиций в социальную сферу, обеспечении гендерного равенства и укреплении принципов общественной солидарности.

\section{Список литературы}

Гуселетов Б.П. (2021) О трансформации института политических партий в эпоху глобализации на примере Европы. Мировая экономика и международные отношения. Том 265, № 5. C. 28-38. DOI: 10.20542/0131-2227-2021-65-5-

Гуселетов Б.П. (2020) Становление института общеевропейских политических партий. Современная Европа, № 4. C. 133-143. DOI: http://dx.doi.org/10.15211/soveurope42020133143.

Кавешников Н.Ю. (2020) Влияние трансформации партийно-политического пространства Евросоюза на организацию и функционирование Европарламента. Современная Европа, № 2. С. 163-175. DOI: http://dx.doi.org/10.15211/soveurope22020163175.

Потемкина О.Ю. (2018) Европейский парламент 2019: подготовка к выборам. Современная Евроna, № 4. C. 35-45. DOI: http://dx.doi.org/10.15211/soveurope420183545

Ривера Э., Дэвис М., Буневич Д., (2019) “Идентичность и демократия”: ультраправые в Европарламенте. Под общ. ред. Крашенинниковой В.Ю. Институт внешнеполитических исследований и инициатив, Москва, Россия. 48 с.

\section{References}

Berman S. (2017) Europe's centre-left risks irrelevance if it can't respond to the populist challenge. EUROPP European Politics and Policy. URL: https://blogs.lse.ac.uk/europpblog/2017/ 02/01/europecentre-left-risks-irrelevance/. (accessed: 12.12.2020)

Beyme, K. von, (1985) Political Parties in Western Democracies, Aldershot: Gower, 444 p.

Clasen, P. (2020) Kaeding, M.; Müller, M.; Schmälter, J. (eds.), "Does the Europarty Still not Matter? European Elections 2019 and the Party of European Socialists", Die Europawahl 2019: Ringen um die Zukunft Europas, Springer, pp. 39-51. DOI: http://dx.doi.org/10.1007/978-3-658-29277-5_4.

Duff, A., (2010) 'Post-national democracy and the reform of the European Parliament,' Policy Paper 42, Notre Europe, $\quad$ Paris. 159 p. URL: https://institutdelors.eu/wpcontent/uploads/2020/08/postnationaldemocracy-democratiepostnationaleduffneoct10-3.pdf.

Day, S., (2014) 'Between "containment" and "transnationalization": where next for the Euro-parties?', Acta Politika, No 49/1, pp. 5-29.

De la Porte C., Heins E. (2016) The sovereign debt crisis, the EU and welfare state reform. London: Palgrave Macmillan. $229 \mathrm{p}$

Guseletov B.P., (2021) O transformatsii instituta politicheskikh partii v epokhy globalizatsii na primere Evropi. [About Transformation of the Institute of Political Parties in the Epoch of Globalization with Europe as an Example]. Mirovaya economica i mejdunarodnie otnoshenia. Vol. 265, No 5, pp. 28-38. DOI: http://dx.doi.org/10.20542/0131-2227-2021-65-5-. (in Russ.).

Guseletov B.P., (2020) Stanovlenie instituta obshcheevropeiskikh politicheskikh partii. [Establishment of the pan European Political Parties Institute]. Sovremennaya Evropa, No 4, pp. 133-143. DOI: http://dx.doi.org/10.15211/soveurope42020133143. (in Russ.).

Habermas, J., (2015) 'Democracy in Europe: Why the Development of the EU into a Transnational Democracy is Necessary and How it is Possible', European Law Journal, No 21 (4): pp. 546-577.

Hanley, D., (1994) The European People's Party: towards a new party form? in D. Hanley (ed.), Christian Democracy in Europe: A Comparative Perspective, London: Pinter Publishers, pp. 185-201.

van Hecke, S., (2010) 'Do transnational party federations matter? (... and why should we care?)', Journal of Contemporary European Research, 6/3, pp. 395-411.

van Hecke, S., (2018) Reconnecting European Political Parties with European Union Citizens, International IDEA Discussion Paper, 6/2018. Strömsborg SE-103 34, Stockholm, Sweden. 71 p.

Hix, S. and Lord, C., (1997) Political Parties in the European Union, Basingstoke: Macmillan. 240 p.

Niedermayer, O., (1983) Europäische Parteien: Zur Grenzüberschreitenden Inter-aktion politischer Parteien im Rahmen des EG [European parties: on the cross-border interaction of political parties in the framework of the European Community], Frankfurt: Campus Verlag, 275 p. 
Potemkina O.Yu. (2018) Evropeiskii parlament 2019: podgotovka k vyboram. [European Parliament 2019; Prepation to Elctions]. Sovremennaya Evropa, No 4, pp. 35-45. DOI: http://dx.doi.org/10.15211/soveurope420183545. (in Russ.).

Raunio, T., (2006) 'Political parties in the European Union', in K. Jorgensen, M. Pollack and B. J. Rosamond (eds), The Sage Handbook of European Union Politics, London: Sage, pp. 247-262.

Reif, K., (1984) 'National electoral cycles and European elections 1979 and 1984', Electoral Studies, $3 / 3$, pp. $244-255$.

Rivera E., Davis M., Bunevich D. (2019) “Identichnost' i demokratiya”: ul'trapravye v Evroparlamente. (Identity and Democracy: extreme right in European Parliament). Krasheninnikova V.Yu., ed. Institut vneshnepoliticheskikh issledovanii i initsiativ. Moscow, Russia. 48 p. (in Russ.).

Schmitt, H., Hobolt, S. and Popa, S., (2014), 'Does personalization increase turnout? Spitzenkandidaten in the 2014 European Parliament elections', European Union Politics, 16/3, pp. 347-68.

Tallberg, J. and Johansson, K., (2008) Party politics in the European Council, Journal of European Public Policy, 15/8, pp. 22-42.

Transnational European Union Towards a Common Political Space. (2009) Edited by W. Kaiser, P. Starie. Published June 18, 2009. Routledge. 260 p.

The Rise of Common Political Order. Institutions, Public Administration and Transnational Space (2017), Edited by J. Trondal, Edward Elgar Publishing, ISBN: 978178643 499 9. 296 p.

Usherwood, S., (2007) Proximate factors in the mobilization of anti-EU groups in France and the UK: the European Union as first order politics, Journal of European Integration, 29/1, pp. 3-21.

Westlake, M. (2017) Possible Future European Union Party-Political Systems, Bruges Political Research Papers, No 60, October 2017. $41 \mathrm{p}$.

Wonka, A. (2010) Decision-Making Dynamics in the European Commission: Partisan, National or Sectoral? in B. Lindberg, A. Rasmussen and A. Warntjen (eds), The Role of Political Parties in the European Union, Oxon: Routledge. 178 p.

\section{The Role of the European Socialists in the EU Political System}

Received 10.02.2021

Author: Guseletov B.P., Doctor of Science (Politics), Senior Researcher at the Center for Party and Political Studies of the Institute of Europe RAS. Address: 11-3, Mokhovaya street, Moscow, Russia, 125009. E-mail: bgusletov@mail.ru

Abstract. The article explores the formation of a single European socio-political space and the evolution of the institution of pan-European political parties (Europarties). It is shown that the growth of practical and scientific interest to the European parties was associated with the gradual strengthening of the role and influence of this relatively new institution in the political system of the EU. The authors identified new trends in the development of the institute of European parties. On the one hand, the confrontation between the supporters of European integration (Eurooptimists) and their opponents (Eurosceptics) has intensified. On the other hand, the format of relations between individual European parties (in particular, the Party of European Socialists, which traditionally supports the expansion of ties between governments and society) with European civil society and key political institutions of the EU (the European Council, the European Commission and the European Parliament) is gradually changing. Based on the analysis of materials related to the activities of the Party of European Socialists (PES) in the last two years, it is shown that this party has managed to create specific tools and mechanisms to strengthen its ties with civil activists (the so-called PES networks on various issues), national member parties, to involve representatives of this party in its work in the European Council, the European Commission and the European Parliament.

Keywords: European Union, European parties, European Parliament, European Commission, Party of European Socialists, European Political Space, European civil Society, national parties.

DOI: http://dx.doi.org/10.15211/soveurope320218393 